\title{
Imagen de la España de la postguerra en un viaje de Gerald Brenan
}

\author{
Giuliana Di FEBo
}

Cuando Gerald Brenan emprende su viaje por España, en el año 1949, lleva ciertamente consigo recuerdos y nostalgia de la tierra en que había vivido años atrás '. Se había marchado en agosto del 36 después de haber sido testimonio ocular, además de corresponsal para Inglaterra, de los convulsos acontecimientos que siguieron al golpe de estado del 18 de julio $^{2}$. El impacto provocado por la tragedia española y la violencia que la siguió, motivaron su investigación historiográfica tendente a individualizar los antecedentes histórico-sociales del conflicto, cuyo fruto fue El Laberinto Español ${ }^{3}$. Este libro le llevó a la fama; publicado en 1943, constituye un precedente de The Face of Spain (traducido al español con el título La faz actual de España) ${ }^{4}$, texto escrito durante su viaje de poco más de dos meses, en 1949, por ciudades y pueblos centro-meridionales. En cierto sentido, el primero constituye el trasfondo histórico al que recurre el autor

- Geraid Brenan vivió en Yegen, un pueblo de la Alpujarra, alrededor de siete años entre 1920 y 1934 , con intervalos para regresar a Inglaterra. Esta experiencia está relatada en el libro $A /$ Sur de Granada, Madrid, Siglo XXI de España, 1991 (13 ed.) (I ed. inglesa 1957). Noticias biográficas y bibliográficas sobre Brenan se encuentran en: J. Gathorne Hardy. The Interior Castle. A Life of Gerald Brenan, London. Sinclair-Stevenson, 1992; y J. Antonio Diaz López, Gerald Brenan Hispanista Angloandaluz, Granada, TAT, 1987.

2 La guerra civil cogió al escritor en Churriana, cerca de Málaga, donde se había instalado en 1934. En los primeros meses de la guerra fue corresponsal del Manchester Guardian y del News Chronicle. De regreso a Inglaterra, a los dos meses del conflicto, hizo emisiones radiofónicas dirigidas a España para la BBC. Véase G. Brenan, Memoria Personal 1920-1975, Madrid, Alianza Tres, 1987 (I ed. 1976).

3 G. Brenan. El Laberinto Español. Antecedentes sociales y políticos de la guerra civil. París, Ibérica de Ediciones y Publicaciones, 1977 (I ed. 1962) (I ed. inglesa 1943).

4 Se utiliza aqui la primera traducción del texto inglés de 1950: G. Brenan. La faz actual de España, Trad. de M. Amilibia, Buenos Aires, Losada, 1952 (los paréntesis en el texto de este articulo indican el número de la página de dicha edición). La última edición española — sin cambios sustanciales - es La faz de España, Trad. de D. Santos, Barcelona, Plaza y Janés, 1985. (I ed. inglesa: The Face of Spain, Turnstile Press, London, 1950; última, London, Penguin Books, 1987). 
cuando ofrece claves de interpretación o informaciones sobre la España franquista: la Falange, los terratenientes, la Iglesia.

Pero Brenan, viajero incansable ${ }^{5}$, también es acompañado por la valiosa guía de K. Baedeker ${ }^{6} \mathrm{y}$, sobre todo, por las sugerencias de las obras de los ingleses $\mathrm{G}$. Borrow y $\mathrm{R}$. Ford, los dos ilustres escritores románticos que en la "diferencia" española habían encontrado una fuente inagotable de exotismo y primitivismo. Veremos cómo esta actitud, asociada a una visión crítica de la realidad española, se mantendrá durante su viaje. La misma estructura del texto, oscilante entre la memorialística, el diario y la crónica periodística, representa un ejemplo emblemático de este género - la literatura de viaje - permanentemente en el confín con la narrativa y otras formas de escritura en primera persona. Brenan es además autor de ensayos sobre temas hispánicos ${ }^{7} y$ de una interesante memorialística ${ }^{8}$ que ofrece a posteriori una clave interpretativa de La faz actual de España.

En su itinerario a través de Andalucía, Castilla y Extremadura, el viajero Brenan toma notas impulsado por la voluntad de entender, como él mismo declara en el prefacio, "el carácter de la cultura y de la civilización española». Este punto de partida, de hecho, se transforma en el libro en una mirada total que abarca caracteres, cultura, personajes, costumbres y paisajes, quizás teniendo en mente aquella inclinación a la "descripción completa" que tanto habia admirado en Richard Ford ${ }^{9}$. Al influjo de los viajeros del ochocientos, unido a su particular conocimiento de la naturaleza (como aprendemos de sus memorias) ${ }^{10}$, se debe tal vez la atención dedicada al paisaje, a menudo simbiosis entre naturaleza, personas y hechos. Es un paisaje - y aflora el romanticismo - que muchas veces refleja experiencias, estados de ánimo, o que se torna proyección de un sufrimiento colectivo.

Dentro de esta tensión que tiende a fijar la globalidad de la experiencia, la guerra civil — vista a través de su prolongada postguerra - se va

5 Véase G. Brenan, Una vida propia, Madrid, Destino 1989 (l ed. inglesa 1962).

6 Se trata del conocido autor de guias del ochocientos. Brenan no cita el titulo de la obra, pero la que probablemente lleva consigo es una edición de Spain and Portugal. Handbook for travellers.

7 Entre las más conocidas obras sobre literatura española: G. Brenan. Historia de la literatura española, Barcelona, Crítica, 1986 (3 ed.) (I ed. inglesa 1951). Este libro, según indica el autor en Memoria Personal (p. 474) fue terminado en febrero de 1949. Además, G. Brenan, San Juan de la Cruz: Biografia, Barcelona, Laya, 1974 (I ed. inglesa 1973).

- Se trata de Una vida propia, op. cit. y Memoria personal, op. cit.

9 La expresión es del Prólogo de Brenan a Richard Ford, Las cosas de España, Madrid, Turner, 1974, pág. 6. Es ésta una de las numerosas guias escritas por el famoso viajero inglés del ochocientos. Su obra está editada en España.

10 Véase ai respecto Una Vida Propia, op. cit. 
estructurando como tema principal alrededor del cual se organizan recuerdos, puntos de vista políticos, excursus históricos, interrogantes, y coordenadas temporales y espaciales. Pero al lado de este núcleo central emerge una manera romántica de mirar a España y a los españoles, que ya se anuncia en el prefacio. Son pocas páginas que emblemáticamente reproducen el esquema del libro. A las anotaciones críticas sobre el franquismo, siguen reflexiones sobre el inmovilismo del carácter de los españoles y la fascinación que, por sus contrastes con Inglaterra, el país ejerce todavía sobre el viajero del siglo XX. La vieja imagen de una España, reserva exótica para el norte de Europa, se vislumbra en la frase final:

"Crisol durante siglos de las culturas de Europa, Asia y el Norte de Africa, España tiene actualmente una tónica que no se parece a ninguna otra. Es una melodía aguda, penetrante, agridulce, a la vez áspera y nostáigica como su música de guitarra, que una vez oída, no puede ya ser olvidada. El septentrional en busca de nuevas sensaciones tiene mil motivos para ir allí» (p. 14).

\section{LA GUERRA CIVIL Y LA POSTGUERRA}

\section{Los personajes}

La representación de la guerra civil como violencia y represión, como juicio y autorreflexión, presente en todas las etapas del viaje, es constantemente evocada por los diálogos, lugares y recuerdos. Un desfile de personajes, todos deseosos de expresar sus opiniones políticas -como él mismo subraya - pueblan el texto de dramáticas tranches de vie, de relatos sintéticos, de valoraciones y anécdotas. Todos están centrados en la participación de los personajes y de sus familiares en los aconteceres de la guerra, o bien, en la desastrada situación del país. Al viajero que interroga se le proporcionan informaciones sobre los salarios, la carestia, el estraperlo, la corrupción de los políticos... Nos enteramos así que los trabajadores tienen que inventar nacimientos y ocultar muertos para conseguir libretas de racionamiento; que oficiales y suboficiales del ejército deben recurrir al pluriempleo, y que en España, "madre del aceite", las raciones consisten en "cien gramos de pan al día y un litro de aceite al mes".

Las predilectas posadas, encrucijada de experiencias y de aventuras para los viajeros del siglo pasado, se vuelven a veces muestras de pobreza y se alternan, en su función de observatorio, con los hoteles, las plazas y los cafés, delineando una topografía de los encuentros ritmada sobre la casualidad. Y la casualidad de los encuentros, unida a la pluralidad de las voces - falangistas, ex-republicanos, monárquicos y franquistas - son el 
fruto de una selección destinada a ofrecer «una buena idea de cómo siente y piensa actualmente el español corriente" y cuyo resultado es una narración "objetiva". La perspectiva dialógica consigue el efecto de esbozar una imagen no preconstituida, en la cual la realidad de los hechos se impone al lector.

Brenan interroga a una muchedumbre, casi siempre anónima, de camareros, chóferes, funcionarios de provincia, curas, campesinos y guias improvisados. Sus relatos no aspiran a encantar al turista ni los guías inventan leyendas, como en los tiempos de los viajeros del siglo diecinueve. Lo que emerge es un cuadro desolador de privaciones, desconfianza y represión; pues un resultado de aquel conflicto fue también la prolongada postguerra que durará hasta comienzos de los años cincuenta.

La guerra se impone como cesura insanable entre pasado y presente. Una cesura que no es sólo cronológica sino que para muchos ha significado la frontera entre la esperanza y la decepción, para otros la revancha del presente. El "antes y el después», evocado por casi todos los interlocutores, subraya continuamente una divergencia de conciencias, de valores, de ideologías y de status sociales.

$Y$ así, el limpiabotas encontrado en Córdoba relata:

"Cuando estalló la guerra civil yo tenía ahorrado algún dinero. Luego, después de la victoria de los nacionalistas, toda la moneda de la zona roja quedó anulada y yo perdi mis ahorros" (p. 45).

Comenta el amigo reencontrado en Churriana:

"Las cosas están hoy mucho peor que antes de la guerra civil. La miseria es atroz. Nunca se ha conocido una miseria así (...). Y sin embargo, Málaga es una de las ciudades más ricas de España» (p. 92).

"Ellos y nosotros», como contraposición pero también como alusión al protagonismo en la misma tragedia, vuelve en las crudas palabras del chófer que había luchado en el bando franquista y que le acompaña en el viaje hasta Viznar:

"Cabe que matáramos a más gente que ellos, pero nosotros no violamos a mujeres, ni torturamos (...). Si - continuó-, entre todos hemos traído la desgracia a España. Antes éramos un país feliz; ahora somos un pais miserable, desgarrado por el odio de un extremo a otro. Apenas se encuentra una familia de la que algunos de sus miembros no hayan sido llevados a la muerte como animales" (pp. 135-136). 
Un pastelero de Pozoblanco, después de haberle hecho una descripción de su fuga a la Sierra, huyendo de «los rojos», comenta amargamente:

\begin{abstract}
«Pero - cuidado-, yo aconsejaría a cualquier nación con tendencias a la guerra civil que optara por cualquier cosa antes de comenzar una guerra así. Estamos hoy mucho peor que en tiempos de la República y nadie sabe cuando volveremos a estar como entonces. Luego, todas esas ejecuciones y represalias destruyen a un pais. El odio que crean durará un siglo» ( $p$. 152).
\end{abstract}

El narrador interviene haciendo preguntas, así como con observaciones y reflexiones orientadas a profundizar y a explicar. Como indicadores de la miseria, a menudo introduce el triste espectáculo de los mutilados de guerra, los mendigos y la extrema pobreza de la indumentaria. Y en la España de 1949 al viajero se le ocurre encontrar una mujer que vive en las cuevas de Sierra Morena, que no puede salir a causa de su vestido "viejo y harapiento que mostraba la carne por los desgarrones"; y otra que no puede ir a misa por no tener ropa decente. $Y$ esto sucede en aquelia misma Andalucía donde el obispo de Granada, según un cuento recogido por Brenan, habría prohibido a los pescadores de El Palo llevar a su virgen protectora a la orilla del mar en ocasión de su fiesta, a menos de "elegir un sitio donde, en los últimos cincuenta años, ninguna mujer se hubiera desnudado".

$Y$ sin embargo, esta miseria que involucra profundamente a Brenan es al mismo tiempo fuente de gozo estético, inmersión en la diferencia generadora de sensaciones primitivas y de recuperación de vitalidad. Refiriéndose a la multitud de vendedores ambulantes que se apiñan en los pasillos del tren que le conduce a Peñón de Vélez comenta:

«Estas escenas constituyen, sin duda, uno de los placeres de viajar por los países meridionales: estimulan el sentido de la vida porque ponen ante nuestros ojos el espectáculo de la lucha por la existencia. Pero iqué pobreza representan!” (p. 82).

El espectáculo del hambre resulta estimulante a los ojos del viajero inglés, hambriento de lo auténtico:

"Esta búsqueda del alimento tan a la vista puede ser aflictiva, pero también, hay que reconocerlo honradamente, estimulante. Llena el ambiente de deseos y ansias. Nos sentimos muy lejos de Bournemouth y Torquay, con sus existencias letárgicas» (p. 83).

El lector aprende la dramática realidad de los hechos reconstruida por los que fueron testimonios oculares. Pero al mismo tiempo se encuentra con el subjetivismo del viajero en "busca del éxtasis", que se deja arrastrar 
por una mirada antropológica que le lleva a definir la alteridad española como combinación de analogías y de desemejanzas ${ }^{11}$. La utilización de la analogía entre la experiencia histórica española y la inglesa - que $\mathrm{G}$. Jackson destaca como un carácter del Laberinto español ${ }^{12}$, en este texto se traslada al plano literario: Valera es el Jane Austín español, Galdós es un Balzac español, con "algo de picante» de Dickens y con la profundidad psicológica de Dostoyeski; el mismo Arcipreste de Hita es un "vehemente Chaucer de España".

Abundan las antítesis vitalidad española/antivitalidad inglesa que fundamentan el mito inglés de la atracción por España: la creatividad y los contrastes de este país sin «medios tonos» frente al monótono positivismo inglés, la belleza del baile gitano frente al cual el Sadler's Wells Ballet es "pálido y superficial", la superior seducción de las mujeres españolas.

Tampoco Brenan se sustrae a la tentación de definir «lo español» o de construir una tipología de los españoles a través del prisma orientalizante de vieja memoria:

“... como las fuerzas centrifugas que son tan poderosas en los paises septentrionales como Inglaterra no existen aquí, los españoles tienen la tendencia a vivir amontonados de un modo que no se ve en ninguna otra parte, salvo en las tierras árabes" (p. 183).

$Y$ aunque le surge la duda de que la gran muchedumbre de vendedores ambulantes y de loterías, limpiabotas, espías y contrabandistas que pueblan las calles es debida a un problema económico, comenta:

"No hace falta remontarse al pasado árabe para ver que se está en una tierra de nómadas..." (p. 188).

O bien, viejos estereotipos que pasan idénticos, a distancia de más de un siglo, de un libro a otro, como la afirmación de que los castellanos odian los árboles, retomada de Ford.

Así, en el año de la sequia, Brenan encuentra al español marcado por la miseria y la dictadura pero también al español marcado por la "selva de los tópicos" 13: orgulloso, simple, sin conflictos, extravagante, perezoso,

\footnotetext{
11 Véase al respecto Francis Affergan. Esotismo e alterità, Milano, Mursia, 1991 (1 ed. francesa 1987).

12 G. Jackson. Homenaje a Gerald Brenan, en A. González Troyano y otros, La imagen de Andalucia en los viajeros románticos y homenaje a Gerald Brenan, Málaga, Diputación Provincial de Málaga, 1987, pp. 157-160.

13 La expresión está tomada del título del libro de Emilio Temprano, La selva de los tópicos, Prólogo de J. Caro Baroja, Madrid, Mondadori, 1988.
} 
que menosprecia la vida; en fin, los yunteros de la meseta, fuertes, recios y laboriosos, se contraponen a los andaluces, urbanos, ágiles, emotivos, habladores y artistas.

\section{Los bandidos}

En esta visión de la postguerra como testimonio de la guerra civil se inserta la representación de otra realidad que emerge de aquel conflicto: los guerrilleros de las sierras ${ }^{14}$. Nuevamente el diálogo introduce la información. En el tren que se dirige a Córdoba, Brenan pregunta a un casual compañero de viaje (un médico con ideas monárquicas) si hay bandidos en la Sierra Morena. La pregunta surge mientras observa el paisaje del paso de Despeñaperros, que de «inmóvil y clásico» se transforma en «pintoresco y romántico» (p. 28). Se tiene la impresión de que el arquetipo de la Andalucía tierra de bandidos, formalizado literariamente en tantos textos de viaje del ochocientos, reaflora en la memoria del viajero como connatural a la morfología del paisaje (un indicador de esto es el uso del adjetivo "pintoresco" 15 que, respecto de España y los españoles, se había transformado en un cliché interpretativo). La confirmación nos llega de la observación sucesiva:

«Es la región clásica del bandidaje español. El mismo José María se hizo célebre aquí hace un siglo» (p. 33).

La alusión al legendario José María, apodado «El Tempranillo» e inmortalizado como prototipo de bandido gentilhombre en las Lettres d'Espagne de Merimée, sigue a la respuesta del médico que le informa sobre la presencia de maquis en la Sierra Morena. El médico, evidentemente influido por la propaganda gubernativa, los estigmatiza como delincuentes y asesinos, proponiendo una versión antitética respecto al modelo romántico del bandido caballero movido por un deseo de justicia social y por una causa revolucionaria ${ }^{16}$. A esta representación Brenan opone

\footnotetext{
${ }_{14}$ Sobre la guerrilla de la posguerra, que también tuvo figuras legendarias como Francisco Sabaté, existe abundante bibliografia; por ejemplo: Eduardo Pons Prades. Guerrillas españolas 1936-1960. Barcelona, Planeta, 1977; Fernanda Romeu Alfaro. La agrupación guerrillera de Levante, Valencia, Alfonso El Magnànim, 1987.

15 El "pintoresco" fue codificado a finales del Siglo XVIII por el escritor W. Gilpin, Three Essays: on Picturesque Beauty; on Picturesque Travel; and or Sketching Landscape; to which is added a Poem on Landscape Painting, London, 1974 (2 ed.).

16 Sobre la tipologia del bandido cfr. Eric J. Hobsbawm, / banditi. // banditismo sociale nell'età moderna, Torino, Einaudi 1971 (traducción de la edición inglesa Bandits, 1971). Para una reconstrucción del bandolerismo en la España del siglo XIX véase J. Zugasti, El bandolerismo. Estudio social y memorias. Prólogo de E. Inman Fox, Madrid, Alianza, 1982.
} 
otro escenario: la represión por parte de la guardia civil y, sobre todo, la imagen romántico-aventurera esbozada en los relatos. Una de las anécdotas que le complace recordar es la del rapto de un rico terrateniente, sentado en un café, por parte de un bandido de la Sierra Nevada disfrazado de capitán de la guardia civil.

La continuidad de antigua tradición entre bandidos y guerrilleros de la Sierra Morena resulta explicita:

“En el monte bajo, a izquierda y derecha, hay lobos, jabalíes y venados, así como bandidos. Cabe leer en la correspondencia de Cicerón referencias a los bandidos que había aqui en la época romana y, desde luego, estas alturas no estuvieron libres de ellos hasta que la Guardia Civil acorraló al último en la década de los ochenta. Ahora, como consecuencia de la guerra civil, han vuelto...» (p. 148).

La asimilación del bandido al paisaje y a la naturaleza reaparece en las proximidades de Extremadura:

“Estos montes estaban poblados por jabalies, lobos y venados y albergaban también a las partidas o bandidos. Se trataba de dominarlos con tropas moras, pero el proceso era lento" (p. 162).

La propia connotación de bandidos, adoptada por el autor las más de las veces ${ }^{17}$, no es ciertamente fruto de la influencia de la propaganda franquista, sino que probablemente refleja la oscilación entre guerrillero, bandido y bandolero presente en $\mathrm{R}$. Ford ${ }^{18}$. Este, entre otras cosas, habia ironizado sobre los fantasiosos relatos de los viajeros, que habian hecho de esta figura una religio loci ${ }^{19}$.

\section{LA CIUDAD, ESPACIO BELLICO. LA TUMBA DE GARCIA LORCA}

En su viaje, a pie, en autobús, en tren, en coche, Brenan, sensible a la naturaleza y las bellezas arquitectónicas que describe detalladamente, no

17 En el texto original inglés Brenan utiliza generalmente los tèrminos bandits y brigands.

18 R. Ford, "Ladrones y precauciones a tomar contra ellos". En Manual para Viajeros por España y Lectores en Casa. Madrid, Turner, 1988, pp. 92-103. El capítulo trata también de las distintas tipologias y formas de organización del bandolerismo. Parece que Ford antes de emprender su viaje compró un salvaconducto de José María, al que sin embargo nunca llegó a ver (citado por Brenan en el Prólogo a Las cosas de España, op. cit., p. 4). Sobre la atracción ejercida por "El Tempranillo" sobre Ford -que llega a compararle a Napoléon Bonaparte- véase $\mathrm{M}$. Bernal Rodríguez, "Tipologías literarias de la Andalucía romántica" en A. González Troyano, op. cit., p. 115).

19 Ibídem, p. 93 
deja de detenerse en lugares donde las huellas de la guerra son todavía evidentes, o bien en monumentos que son fuente de evocación de acontecimientos bélicos.

La recuperación de la memoria - siempre conmensurada con el presente- empieza con su llegada a Madrid, mítica capital de la guerra. La representación de la postguerra se configura en el contraste entre los coches norteamericanos y los mutilados que se arrastran por las calles o en las palabras del camarero que le ponen al tanto del mercado negro, "el único negocio verdaderamente floreciente del país". Se trata de un Madrid cuyos alrededores están todavia surcados de trincheras y que muestra, en el centro, edificios reconstruidos después de la guerra, borrando las ruinas.

Málaga y Churriana son en cambio los lugares donde la reevocación está asociada a la experiencia personal vivida trece años antes. Enseguida el recuerdo reanuda la secuencia de violencias y matanzas a las que asistió durante los primeros dos meses del conflicto. $Y$ aquí es su autorrepresentación que se coloca entre pasado y presente. La preocupación por la acogida que le sería reservada en cuanto simpatizante de la causa republicana resulta muy pronto superada por la manifiesta aceptación por parte de los habitantes del país. Asimismo, rápidamente queda atrás el temor de encontrar en condiciones desastradas la casa de Churriana donde había pasado cuatro años de su vida. La casa es espacio evocador de episodios acaecidos durante aquellos frenéticos días: entre otras cosas, el ocultamiento de un falangista para salvarle de los Comités de la $\mathrm{FAl}^{20}$. Pero en el presente es lugar de peregrinación de marginados solicitando ayuda para sobrevivir.

El viaje a Granada tiene como fin la búsqueda de la tumba de Garcia Lorca, en esa época meta de tantos antifranquistas. A esta etapa Brenan dedica un capítulo del libro, posteriormente publicado como artículo separado ${ }^{21}$, que proporcionará una importante referencia para el libro de lan Gibson sobre la muerte de García Lorca ${ }^{22}$.

Es una Granada triste la que se le presenta después de quince años, con su Plaza de Bibarrambla antes "tan alegre y llena de vida" y ahora

20 El episodio está relatado en Memoria personal, op. cit. En La Faz de España (p. 67) el autor nos informa que la historia está ampliamente relatada por su mujer, acompañante silenciosa en el viaje, en el libro de Gamel Wolsey, Death Other Kingdom.

21 G. Brenan, "La verité sur la mort de Lorca", en Les nouvelles Litteraires, N. 31, 5, 1951.

22 Ian Gibson, La represión nacionalista de Granada en 1936 y la muerte de Federico Garcia Lorca, Paris, Ruedo Ibérico, 1971. 
«muerta, como exangüe». Es la ciudad que ha sufrido durante la guerra un gran número de ejecuciones de republicanos y ahora aparece invadida por la policía. El símbolo de su modernización es la enorme sucursal del Banco de España, construida en la Gran Vía:

"Estos nuevos bancos, levantados con el beneficio de la inflación, son al presente régimen lo que las grandes catedrales eran a la Edad Media. Simbolizan la pasión de dominio" (p. 116).

El Albaicín, espacio oriental que tanto había entusiasmado a los Merimée, Gautier, Ford, Hugo e Irving, se transforma para Brenan en espacio emotivo y doloroso en tanto que evocación del poeta asesinado. De repente, surge la idea de visitar la tumba de Federico. Las páginas que siguen narran la triste peregrinación y son de las más intensas del libro.

Un imaginario de muerte aletea sobre el dramático itinerario. El cielo azul «parece compadecerse de todo este dolor» y el camino que pasa por la avenida del Generalife - cuyo encanto oriental es desatendido- evoca el paso de los camiones cargados de prisioneros. Y la guerra sobrevive en los muros del cementerio, donde todavía aparecen las señales de las balas.

En el cementerio de Granada, la penosa búsqueda se vuelve aún más trágica a causa del cinismo de los sepultureros, las informaciones falsas y el silencio sobre la ubicación de los restos de García Lorca. Se llega hasta lo goyesco - comenta el autor-cuando en un pozo encuentra el cadáver momificado de un coronel de la Guardia Civil, puesto allí a vigilar "los restos de los rojos que sus sucesores han fusilado" (p. 101).

Las ejecuciones cotidianas están todavia vivas y presentes en el recuerdo de las personas entrevistadas, como si «hubieran ocurrido ayer»:

«Describieron el bramar nocturno de los camiones que subían por la cuesta del cementerio y después las descargas... Todas las mañanas, las esposas y las madres de los detenidos subian también a la colina para buscar entre los cadáveres a sus hombres» ( $p .125)$.

Frente a estos relatos, Brenan se interroga continuamente sobre las causas de un evento tan devastador. Encuentra su origen en un carácter casi congénito de autodestrucción de los españoles:

«El amor nato de los españoles por la destrucción, su obsesión de la muerte y su tendencia al fanatismo hallaban satisfacción plena en estas orgiásticas escenas, porque no había autoridad civil o religiosa, fuerza moral o inhibición que pudiera detenerlas" (p. 125).

La etapa a Fuente Vaqueros, el pueblo donde nació García Lorca, suscita en la mirada del viajero correspondencias entre lugares, personas, naturaleza y animales, amalgamados en una soledad común: 
"(...) se veía el habitual grupo de mozos de labranza sin trabajo, de miradas fijas que no ven, de rostros sin expresión. Mulas, carros de bueyes, cerdos, cabras, chiquillos... Todo el pueblo parecía una vasta granja; olia a tie. rra de labor y a rotación de faenas campesinas» (p. 129).

La peregrinación termina en el barranco sembrado de centenares de túmulos, donde, según indican voces anónimas, se encontrarían los restos del poeta. El postrer saludo de Brenan a Federico es una inmersión en la última visión de la naturaleza captada por el poeta, fusilado

«... mientras el alba iba iluminando el cielo y el canto de los gallos llegaba desde el llano en distantes ecos» (p. 135).

El viaje continúa hacia Córdoba. La visión del río sugiere «una escena que parecía salir de las páginas de Borrow». Ciudad rica en tradiciones arquitectónicas y literarias, donde el viajero se demora en las mezquitas y en la casa de Góngora; pero también espacio marcado por los desocupados, por una "pobreza horripilante" y por los recuerdos de la represión: en la Catedral, una placa de mármol lleva los nombres de los sacerdotes de la diócesis asesinados durante las primeras semanas de la guerra.

Y después La Mancha, Castilla y Extremadura. Ciudad Real, Badajoz y Medellín evocan secuencias históricas ritmadas por grandes y pequeñas batallas: desde aquélla de Alarcos en 1195, librada y ganada por los moros contra Alfonso de Castilla, a la destrucción del ejército español por parte de los franceses. Y aquí la representación de la matanza realizada por el mariscal Victor durante la guerra de la Independencia, parece presagiar la futura tragedia:

"Murieron diez mil hombres, cuyos huesos permanecieron alli mismo blanqueándose durante muchos años. Víctor, un completo salvaje, fusiló a sus prisioneros y saqueó el pueblo, destruyendo deliberadamente la casa de Cortés" ( $p .171$ ).

Preexistente en el imaginario del viajero a través de la descripción de Borrow ${ }^{23}$, Badajoz es recordada como nostalgia de un paisaje idilico enturbiado por la desmedrada cotidianeidad del presente:

23 Se trata del conocido libro The Bible in Spain, publicado en 1842, que relata el viaje a España de George Borrow entre 1836 y 1840, por cuenta de la Sociedad británica, para difundir el Nuevo Testamento sin notas. La obra fue traducida y prologada en España por Manuel Azaña en 1921 Recientemente se ha vuelto a publicar: G. Borrow. La Biblia en España, Madrid, Alianza, 1993. 
“Es junto al rio donde el carácter oriental de Badajoz se hace más manifiesto. No hay lavanderas que canten como aquellas sirenas de los tiempos de Borrow - poca gente canta hoy en España- pero son muchas las mujeres que llevan fardos y cántaros sobre la cabeza" (p. 177).

En sus murallas del setecientos la ciudad conserva marcas de eventos bélicos pasados y recientes. La guerra civil está allí dibujada por una brecha y por una lápida en memoria del asalto de la Legión Extranjera, en agosto de 1936. El recuerdo de la tristemente famosa matanza de republicanos que la siguió, en la arena y en la plaza de la catedral, suscita juicios amargos y el fusilamiento de los prisioneros propone la continuidad con "la cruel costumbre de la primera guerra carlista».

El camino continúa hacia Toledo, anunciada por áridas mesetas, y como es típico en la literatura de viaje- surgen memorias de las descripciones de viajeros precedentes. Esta vez es R. Ford quien definió esta tierra «región sarnosa que causa pesadumbre».

La visita al Alcázar, donde tuvo lugar la mítica resistencia del general franquista Moscardó, que no se rindió ni siquiera ante el fusilamiento del hijo, es la ocasión para una valoración negativa de la actuación republicana y para consideraciones sobre el retraso de la caída de Madrid, precisamente debido a la encarnizada defensa del Alcázar. Pero Toledo, ciudad del Cid, de Santa Teresa, de Bartolomé Carranza y de El Greco (al cual el autor dedica algunas páginas) es también espacio-símbolo de la alianza del poder eclesiástico con el estado. $Y$ a la iglesia, impasible y silenciosa frente a la represión franquista, Brenan hace a menudo referencia en el texto, aunque no deja de criticar la destrucción efectuada durante la guerra de tesoros artísticos de las iglesias por parte de los republicanos. Así como a veces aparece la ironía protestante frente a las vírgenes, definidas «muñecas» o frente a los santos españoles, «los más sosos de Europa».

En las etapas sucesivas, en Aranjuez y Madrid, se tiene la impresión de que el viajero se limita a un papel de observador turístico y hedonístico.

Aranjuez, la ciudad en la cual todo habla «el lenguaje del placer y del formalismo del Siglo XVIII», ha perdido el sonido de las cascadas que habia oido en el 34 , debido a la prolongada sequía. A su regreso, Madrid se presenta como una capital llena de vida donde puede ver las procesiones de la Semana Santa, mujeres vestidas de penitentes, cafés repletos, y chicas exhibiendo en el paseo sus atractivos juegos de gestos y miradas; las viejas, en cambio, «tan delgadas y leves», nunca están alegres, y -anota Brenan- “sólo los viejos saben lo que han perdido".

$Y$ de nuevo el viajero registra sus emociones ambivalentes: 


\begin{abstract}
"Pero, de todos modos, ¡qué ciudad más dramática es Madrid! El sentido moral puede escandalizarse a veces ante el contraste entre ricos y pobres, pero no hay modo de no sentir el estímulo de tanta vitalidad. Los españoles se abandonan al placer y al dolor de manera más abierta y completa que cualquier otra raza" (p. 235).
\end{abstract}

En fin, la vuelta a Inglaterra, después de haber conocido por los periódicos que la sequia ha terminado. La llegada a Londres, "pulcra como un jardín", proporciona la ocasión para comparar las dos capitales. El recuerdo de las "ásperas voces íberas" y de las "caras dramáticas de los madrileños" frente a las "vegetales y plácidas» de los ingleses, origina un breve diálogo interior en el cual el viajero, turbado por sensaciones confusas, se interroga sobre su país. Algunas referencias a sus «facultades acondicionadas a lo español» y a sentirse "medio extranjero", acompañadas de apreciaciones sobre la incapacidad de los ingleses para practicar "las artes de la vida" y sobre su excesivo utilitarismo, harían pensar en una transformación de la identidad del viajero.

Al concluir el libro, Brenan tiende a recuperar la vitalidad y el espíritu de aventura interiorizados por los ingleses, junto a su sentido de "cohesión nacional». El fiel de la balanza se orienta decididamente a favor de Inglaterra:

«Si, pese al moho de su espíritu, a su prosaico positivismo y a su miedo a la realidad, este pais era un pais al que valía la pena pertenecer. Era misterioso, era complejo y era honrado. En todo caso, cabía decir de él, como Orwell lo habia hecho, que era un pais cuyos habitantes no se mataban los unos a los otros. $Y$ esto, cuando, como, en mi caso, se venía de España, significaba algo" (p. 249).

La guerra civil española vuelve, en su absurda brutalidad, a cerrar el círculo de las reflexiones y del viaje. 